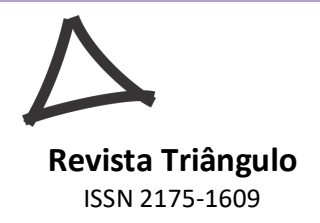

\title{
INTEGRAÇÃO LATINO-AMERICANA PARA A EDUCAÇÃO INFANTIL: EM FOCO AS POLÍTICAS INTERSETORIAIS RECOMENDADAS PELA UNESCO
}

\author{
LATIN AMERICAN INTEGRATION FOR CHILD EDUCATION: FOCUS ON \\ INTERSECTORAL POLICIES RECOMMENDED BY UNESCO
}

\section{INTEGRACIÓN LATIN-AMERICANA PARA LA EDUCACIÓN INFANTIL: EN FOCO LAS POLÍTICAS INTERSECTORIALES RECOMENDADAS POR LA UNESCO}

\author{
Camila Maria Bortot \\ Universidade Federal do Paraná (UFPR) Bolsista CAPES. \\ E-mail: camilabortot@hotmail.com \\ Angela Mara de Barros Lara \\ Universidade Estadual de Maringá (UEM) \\ E-mail: angelalara@ymail.com
}

\section{RESUMO}

O objetivo do presente artigo é analisar as orientações propaladas pela Organização das Nações Unidas para a Educação, a Ciência e a Cultura (Unesco) com relação às políticas para a infância nos relatórios Participación de Las Familias en La Educación Infantil Latinoamericana e Síntesis Regional de Indicadores de La Primera Infancia, ambos de 2004. Ilustrado por meio de mapas conceituais, os documentos evidenciam 'boas práticas' de programas de países da América Latina e orientam que a educação na primeira infância é uma oportunidade para se assegurar melhores resultados nas posteriores etapas educacionais, tendo em vista que uma experiência educativa bem-sucedida nos primeiros anos ocasiona importantes benefícios sociais, educativos e econômicos no futuro. Tais orientações sinalizam uma Agenda Regionalmente Estruturada, para a etapa analisada, focada em ações intersetoriais entre educação-saúde das crianças e de suas famílias. Conclui-se que a ênfase em práticas intersetoriais se figuram como um dos antídotos para o alívio e a gestão da pobreza, bem como a manutenção do capital humano futuro, prefigurando, tendencialmente, uma determinada dinâmica geopolítica que envolve as políticas para a educação infantil na América Latina.

Palavras-chave: América Latina. Educação Infantil. Políticas Intersetoriais. UNESCO.

\begin{abstract}
The present article aimed to examine the orientations proposed by the United Nations Education, Scientific and Cultural Organization on reports Participación de Las Familias em La Educación Infantil Latinoamericana and Sintesis Regional de Indicadores de La Primera Infancia, both dated 2004. Illustrated through conceptual maps, the documents highlight 'good practices' of Latin American country programs, and, point out that early childhood education is an opportunity to ensure better outcomes in later education, since a successful educational experience in the early years brings important social, educational and economic benefits in the future. These guidelines point to a Regionally Structured Schedule for the analyzed stage, through intersectoral actions between education-health of children and their families. It is concluded that the emphasis on intersectoral practices is one of the antidotes for the relief and poverty management, as well as the maintenance of future human capital, to prefigure, tendentially, in the geopolitical dynamics that involve policies for early childhood education in Latin America.
\end{abstract}

KEYWORDS: Latin America. Child education. Intersectoral policies. Unesco. 
RESUMEN

El objetivo del presente artículo fue examinar las orientaciones propuestas por la Organización de las Naciones Unidas para la Educación, la Ciencia y la Cultura en los informes Participación de Las Familias en La Educación Infantil Latinoamericana y Sintesis Regional de Indicadores de La Primera Infancia, ambos datados en 2004. Ilustrado por medio de Mapas Conceptuales, los documentos evidencian 'buenas prácticas' de programas de países de América Latina, y, orientan que la educación en la primera infancia es una oportunidad de asegurar mejores resultados en la educación posterior, teniendo en cuenta que una experiencia educativa exitosa en los primeros años ocasiona importantes beneficios sociales, educativos y económicos en el futuro. Tales orientaciones señalan a una Agenda Regionalmente Estructurada para la etapa analizada, a través de acciones intersectoriales entre educación-salud de los niños y de sus familias. Se concluye que el énfasis en prácticas intersectoriales se sitúa como uno de los antídotos para el alivio y gestión de la pobreza, así como el mantenimiento del capital humano futuro, para desarrollar, tendencialmente, en la dinámica geopolítica que envuelven las políticas para la educación infantil en América Latina.

PALABRAS-CLAVE: América Latina. Educación infantil. Políticas intersectoriales. Unesco.

\section{INTRODUÇÃO}

O presente artigo se circunscreve à temática da integração latino-americana em uma agenda estruturada para a infância, sobretudo, a educação infantil, a partir da primeira década do século XXI. Tal agenda envolve recomendações aos países signatários da Organizações das Nações Unidas (ONU), cercados pelas disputas econômicas e políticas da geopolítica internacional e dos processos multilaterais. Percebe-se que, de um lado, há um discurso social e político sobre a infância de direitos, ao passo que, de outro, percebem-se práticas sociais relacionadas com as crianças que não garantem seus direitos fundamentais.

Objetivou-se analisar, neste texto, as orientações propaladas pela Organização das Nações Unidas para a Educação, a Ciência e a Cultura (UNESCO) nos relatórios Participación de Las Familias en La Educación Infantil Latinoamericana (2004a) e Síntesis Regional de Indicadores de La Primera Infancia (2004b). Ao revisitar relatórios do início do século e realizar tal análise, tivemos como problemática central: Quais as perspectivas teóricas que fundamentam as recomendações dos relatórios da Unesco para as políticas de educação infantil dos países latino-americanos, tendo em vista a dinâmica geopolítica mundial?

A metodologia adotada foi de caráter documental, tomando como instrumento Mapas Conceituais (MC). O uso de documentos exige apreciação e valoração, considerando que são frequentemente contraditórios e, por isso, devem ser lidos em relação ao tempo e contexto particulares em que foram produzidos, além de também serem confrontados com outros do 
mesmo período e local (SHIROMA; CAMPOS; GARCIA, 2005; SÁ-SILVA; ALMEIDA; GUINDANI, 2009). Dessa forma, os dados coletados foram analisados à luz da produção acadêmica acumulada na área do estudo em tela, e se justifica pela articulação de práticas e políticas educativas intersetoriais que integram o eixo saúde-educação-nutrição, bem como uma articulação voltada para a educação das crianças e de suas famílias, considerada a integração/homogeinização de práticas, sobretudo as voltadas à gestão da pobreza.

Em relação à elaboração dos $\mathrm{MC}$, utilizou-se o software Cmap Tools, que é uma ferramenta distribuída gratuitamente pelo Institute for Human Machine Cognition da University of West Florida (IHMC). Os MC, que são diagramas que relacionam conceitos, apontam as orientações, objetivos e encaminhamentos de cada relatório. A apresentação dos dados deu-se da seguinte forma: apresentação do documento, MC e discussão dos dados, buscando categorizar e discutir as similitudes.

Nesse sentido, num primeiro momento, realizou-se uma contextualização histórica sobre uma agenda estruturada para a educação infantil na América Latina, para, posteriormente examinar os relatórios da UNESCO supracitados e, por fim, tecer considerações finais.

\section{CONSTRUÇÃO DE UMA AGENDA PARA A INFÂNCIA NA AMÉRICA LATINA - APORTES HISTÓRICOS}

Ao mesmo tempo em que se procura respeitar os direitos da criança, muitas delas vivem em condições adversas, enfrentando precárias condições de vida. Conforme Pinto e Sarmento (1997), as crianças sempre estiveram presentes no mundo, contudo, as condições de vida que atualmente presenciamos produziram novas relações, o que tem gerado discussões e preocupações. O conceito de infância não corresponde a uma categoria universal e de significado óbvio, tem seu significado demarcado por condições materiais e realidade social históricas.

A necessidade de proporcionar proteção especial à criança foi enunciada em vários documentos internacionais: Declaração de Genebra sobre os Direitos da Criança, de 1924; Declaração sobre os Direitos da Criança, adotada pela Assembleia Geral das Nações Unidas, em 20 de novembro de 1959; Pacto Internacional de Direitos Econômicos, Sociais e Culturais, também de 1966 (art. 10) ${ }^{1}$. E ainda integra estatutos e instrumentos relevantes das 
agências especializadas e organizações internacionais que se dedicam ao bem-estar da criança.

O debate universal sobre a infância se intensifica por meio da Convenção dos Direitos da Criança, realizada em 20 de novembro de 1989 pelas Nações Unidas, em Nova York, que consagrou um conjunto de direitos próprios e inalienáveis das crianças, oficializado no ano seguinte como lei internacional. A Convenção teve como meta incentivar os países membros a implementarem processos de desenvolvimento pleno e harmônico da personalidade de suas crianças, favorecendo o seu crescimento no ambiente familiar em clima de felicidade, amor e compreensão, preparando-as plenamente para viverem em sociedade e serem educadas no espírito dos ideais proclamados na Carta das Nações Unidas, em espírito de paz, dignidade, tolerância, liberdade, igualdade e solidariedade. Ressalta o preâmbulo da Convenção a importância da cooperação internacional para a melhoria das condições de vida das crianças em todos os países, em particular nos países em desenvolvimento, onde se concentra um grande número de crianças social e economicamente marginalizadas. E, para que isso se faça, a fim de incentivar, viabilizar e acompanhar a implementação da Convenção sobre os Direitos da Criança, estimulando a cooperação internacional, o Estado-membro pode criar um comitê e convidar organismos internacionais especializados, o Fundo das Nações Unidas para a Infância (UNICEF) e outros órgãos das Nações Unidas para assessoramento ao país interessado, fornecendo cópias de relatórios e solicitando novos relatórios desses organismos, os quais poderiam, igualmente por iniciativa própria e dentro de suas atribuições, se fazerem representados nos respectivos Estados-membros na ocasião da análise da implementação das disposições da Convenção (art.45).

A América Latina e o Caribe foram os primeiros a ratificar o documento da Convenção. Segundo Méndez (2001), sua aprovação e difusão na região coincidiu com o retorno à democracia em vários países, o que permite sugerir que a linguagem progressista dos novos direitos da criança se ajustava e impulsionava a reconstrução da democracia na região, bem como a relacionava à agenda política internacional. No movimento do global para o local buscou-se uma corrente que se distanciasse dos movimentos políticos e econômicos que foram base de sustentação dos países ocidentais e orientais nas últimas décadas, e que, com o movimento de globalização latente, não oferecem respostas efetivas aos problemas decorrentes da internacionalização de processos e produtos. Tal ideologia pode então ser um construto para atingir a perfeição ou a dominação, ancorando-se na ideologia social-liberal. 
Os organismos internacionais buscaram fazer da questão social a globalização com face mais humana. Além dos organismos internacionais estudados, podemos verificar que, a partir de 1990, a CEPAL publicou uma série de relatórios ${ }^{2}$ com o objetivo de adequar a instituição para a versão atual do socialismo burguês, ou social-liberalismo, ou terceira via, a fim de combinar projetos políticos, sobretudo para países de saída de regime ditatorial, de estabilização econômica e reestruturação produtiva, concluindo pela promoção de medidas sociais compensatórias. A adesão da CEPAL às medidas social-liberais foi marcante: realizando uma tímida revisão das teses do receituário do neoliberalismo, aplicou-se um reformismo-restaurador nessa região periférica. Na avaliação de Carcanholo (2010, 138-139):

A agenda cepalina de 'reforma das reformas' parece significar muito mais um gerenciamento das 'imperfeições' das reformas neoliberais do que uma concepção significativamente distinta de desenvolvimento. No passado, a Cepal caminhava em sentido contrário ao ideário liberal-conservadorortodoxo. Atualmente, acompanha o pensamento convencional, isso quando não vai a reboque ao revisionismo, com seu modelo de 'reforma das reformas'.

Na virada neoliberal e na emergência da terceira via nos países em desenvolvimento, percebemos que a receita capitalista aponta para um ajuste global coerente com os ditames da mundialização do capital e das novas formas de sociabilidade. No Hemisfério Sul do mundo, nos países periféricos, é preciso reformar para ocorrer uma integração competitiva na nova divisão internacional do trabalho, mas sob as condicionalidades dos programas de ajuste monitorados pelo Banco Mundial e pelo Fundo Monetário Mundial (FMI). Esse movimento do global para o local das políticas educativas apresenta-se, conforme conceitua Dale (2004), como agenda globalmente estruturada para a educação, modelada pelas relações globais e pelo contexto nacional configurado sob tais relações, implicando, assim, uma enxurrada de mandos e modelagens para o trabalho educativo. Tratamos da Convenção para compreender a presença da agenda internacional sobre a infância nos programas de atendimento aos países.

Ao tratar da agenda global, temos de compreender o que Dale (2004) denomina Cultura Educacional Mundial Comum $\left(\mathrm{CEMC}^{3}\right)$. Essa teoria sustenta a existência de uma cultura mundial comum desenvolvida há séculos, que explica a emergência e o desenvolvimento de algumas instituições na contemporaneidade como o Estado-nação e a escolarização de massas. Segundo o autor anteriormente citado, tanto na massiva e rápida expansão dos sistemas de educação nacionais quanto no inesperado isomorfismo global das 
categorias curriculares em todo o mundo, pressupõe-se uma educação que tem uma missão modernizadora para os modelos de sociedade baseados em padrões comuns e universalizados.

Dale (2001) traz como problemática para a discussão da CEMC e da AGEE: Como o sistema mundializado afeta as políticas e práticas da educação nacional? As aspirações da CEMC estão ligadas à existência e à natureza de um conjunto universal de normas, valores e ideias que modelam a natureza do Estado. Já AGEE busca identificar uma mudança de paradigma acerca da globalização que tem mudado o papel do Estado, tanto nacional quanto internacionalmente. Essa mudança, marcada por processos de globalização, impactou o Estado e os sistemas e políticas educativas, usando mecanismos que podem ser especificados e seguidos.

Após as considerações firmadas em 1989 e a presença de uma agenda comum, estabelece-se um contraponto em torno da diversidade de formas e modos de organização e da heterogeneidade de programas e políticas que parecem indicar mais para processos fragmentários e localizados do que para concepções mais sistêmicas e estruturadas e acordadas regional ou globalmente para esta etapa educativa da educação infantil. Para Campos (2008, p. 30):

Uma análise sobre o desenvolvimento da Educação Infantil em diferentes países da América Latina, bem como um exame de documentos sobre esse nível educativo, produzido por organismos internacionais que têm dedicado uma farta produção a essa área, como UNESCO e UNICEF, permitem-nos concluir que a partir dos anos de 1990 emerge um interesse renovado pela educação das crianças pequenas, observando-se uma expressiva, ainda que não suficiente, ampliação na oferta e obrigatoriedade desse nível educativo.

Desde 1990, quando países de todo o mundo se reuniram em Jomtien para referendar o compromisso global Educação para Todos, firmando o preceito de 'educação ao longo da vida', a educação das crianças pequenas tem sido foco de atenções. No entanto, os avanços registrados estão muito aquém das metas e dos compromissos assumidos pelos países participantes. De acordo com a UNESCO (2010), na América Latina a taxa bruta de escolarização das crianças entre 3 e 5 anos passou de 56\% a 65\% no período de 1999 a 2007; entre 2002 e 2008 , o crescimento foi da ordem de $2 \%$ ao ano.

Esses percentuais ocultam, no entanto, profundas disparidades tanto intra quanto interpaíses, assim como dos segmentos etários atendidos, das crianças natimortas ou daquelas denominadas 'resíduos' de serviços de saúde, uma vez que nem tiveram a oportunidade de 
viver. Para todas essas crianças não há política de educação, pois a elas esse direito foi negado, direta ou indiretamente - são as crianças invisíveis. Esses dados podem ser compreendidos no Quadro 1.

Quadro 1 - Taxas de matrícula por idade na América Latina

\begin{tabular}{|c|c|c|c|}
\hline País & 3 anos & 4 anos & 5 anos \\
\hline Argentina & 34,1 & 70,0 & 100,0 \\
\hline Bolívia & 0,2 & 20,4 & 66,3 \\
\hline Brasil & 24,3 & 43,5 & 62,4 \\
\hline Chile & 22,2 & 80,5 & 87,3 \\
\hline Colômbia & 22,4 & 44,9 & 80,2 \\
\hline Costa Rica & - & - & - \\
\hline Cuba & 98,1 & 100,00 & 100,0 \\
\hline Equador & 6,2 & 17,5 & 82,1 \\
\hline El Salvador & - & - & - \\
\hline Guatemala & 2,9 & 13,5 & 35,4 \\
\hline Honduras & 4,7 & 24,8 & 53,8 \\
\hline México & 33,0 & 92,0 & 100,0 \\
\hline Nicarágua & 34,2 & 55,2 & 83,2 \\
\hline Panamá & 6,0 & 41,1 & 82,2 \\
\hline Paraguai & 3,9 & 21,4 & 72,1 \\
\hline Peru & 54,0 & 75,6 & 87,9 \\
\hline Rep. Dominicana & 14,6 & 26,7 & 66,5 \\
\hline Uruguai & 63,0 & 88,0 & 95,0 \\
\hline Venezuela & 46,0 & 72,4 & 87,1 \\
\hline
\end{tabular}

Fonte: UNESCO (2010)

Com o estudo do BID em 2016 se resume a proporção de crianças, desde o nascimento até os 3 anos de idade, em creches de áreas urbanas e rurais separadamente, em sete países para os quais há dados disponíveis: Brasil, Chile, Colômbia, Equador, Guatemala, Nicarágua 
e Uruguai. Os dados revelam um aumento acentuado do uso de creches em alguns países: no Brasil e no Chile, a proporção de crianças em creches duplicou na última década, e no Equador aumentou seis vezes; no Brasil, no Chile, na Colômbia e no Equador, entre um quinto e um terço de todas as crianças de 0 a 3 anos de idade está em creches; na Nicarágua e, em especial, na Guatemala, o número é bem menor. Em todos os países, com exceção do Equador, a proporção de crianças em creches é substancialmente maior nas áreas urbanas em comparação com as rurais. (vide Quadro 2)

Quadro 2 - Matrículas em creche oferecidos em Centros de Educação Infantil (\%)

\begin{tabular}{|l|l|l|l|l|l|l|}
\hline \multicolumn{3}{|c|}{ No00 } & \multicolumn{3}{c|}{ U010 } \\
\hline País & Nacional & Rural & Urbano & Nacional & Rural & Urbano \\
\hline Brasil & 11,7 & 4,5 & 13,3 & 21,2 & 9,4 & 23,5 \\
\hline Chile & 11,4 & 3,4 & 12,6 & 26,1 & 15,7 & 27,5 \\
\hline Colômbia & n.d. & n.d. & n.d. & n.d. & 13,5 & 34,0 \\
\hline Equador & 3,7 & 2,8 & 4,3 & 23,2 & 23,1 & 23,3 \\
\hline Guatemala & 1 & 0,5 & 2,1 & 1,2 & 0,5 & 2,2 \\
\hline Nicarágua & 8 & 6,4 & 9,3 & 7,6 & 7,4 & 7,7 \\
\hline Uruguai & 21,7 & 5,4 & 22,9 & 35,1 & 20,7 & 37,7 \\
\hline
\end{tabular}

*n.d. = não disponível.

Fonte: Adaptado de BID (2016)

Vale ressaltar, ainda, que as orientações e ações mediadas pelos OIs para a educação infantil, segundo Rosemberg (2002), implicaram não apenas incentivos e políticas de indução à expansão desse nível de atendimento educacional via instituições não-formais, como também uma mudança no modus operandi desses organismos, que ampliaram seu raio de atuação para além do tradicional binômio saúde-nutrição, envolvendo-se em projetos educativos destinados à infância e à juventude, tendencialmente a práticas intersetoriais. Para entender tal mediação, pautada pela hegemonia presente na AGEE e uma tendência à promoção de políticas intersetoriais na América Latina, examinaremos, no próximo item, os 
relatórios Participación de Las Familias en La Educación Infantil Latinoamericana (2004a) e Síntesis Regional de Indicadores de La Primera Infancia (2004b).

\section{A ÊNFASE INTERSETORIAL PARA A EDUCAÇÃo INFANTIL NA AMÉRICA LATINA}

Os MC sintetizam elementos-chave da discussão apontada nos documentos, que convergem entre si ao tratar especificamente da região latino-americana. Primeiro, apresentaremos o MC do documento Participación e, em seguida, o documento Síntesis.

O relatório Partipación de las Família em la Educación Infantil Latinoamericana foi publicado pela UNESCO em 2004. O documento se coloca como um projeto que tem por objetivo: Identificar ministérios e organizações que trabalham na educação e no apoio aos pais responsáveis; Analisar e sistematizar políticas e programas educacionais na participação, educação familiar e apoio para os pais; Realizar encontros regional e nacional para trocar informações e experiências sobre participação, educação e apoio aos pais; Estabelecer um fórum permanente regional para discutir o intercâmbio de políticas e programas de participação, educação familiar e apoio para os pais. 
FIGURA 1 - MC 1: PARTICIPACIÓN DE LAS FAMILIAS EM LA EDUCACIÓN INFANTIL LATINOAMERICANA (UNESCO, 2004A)

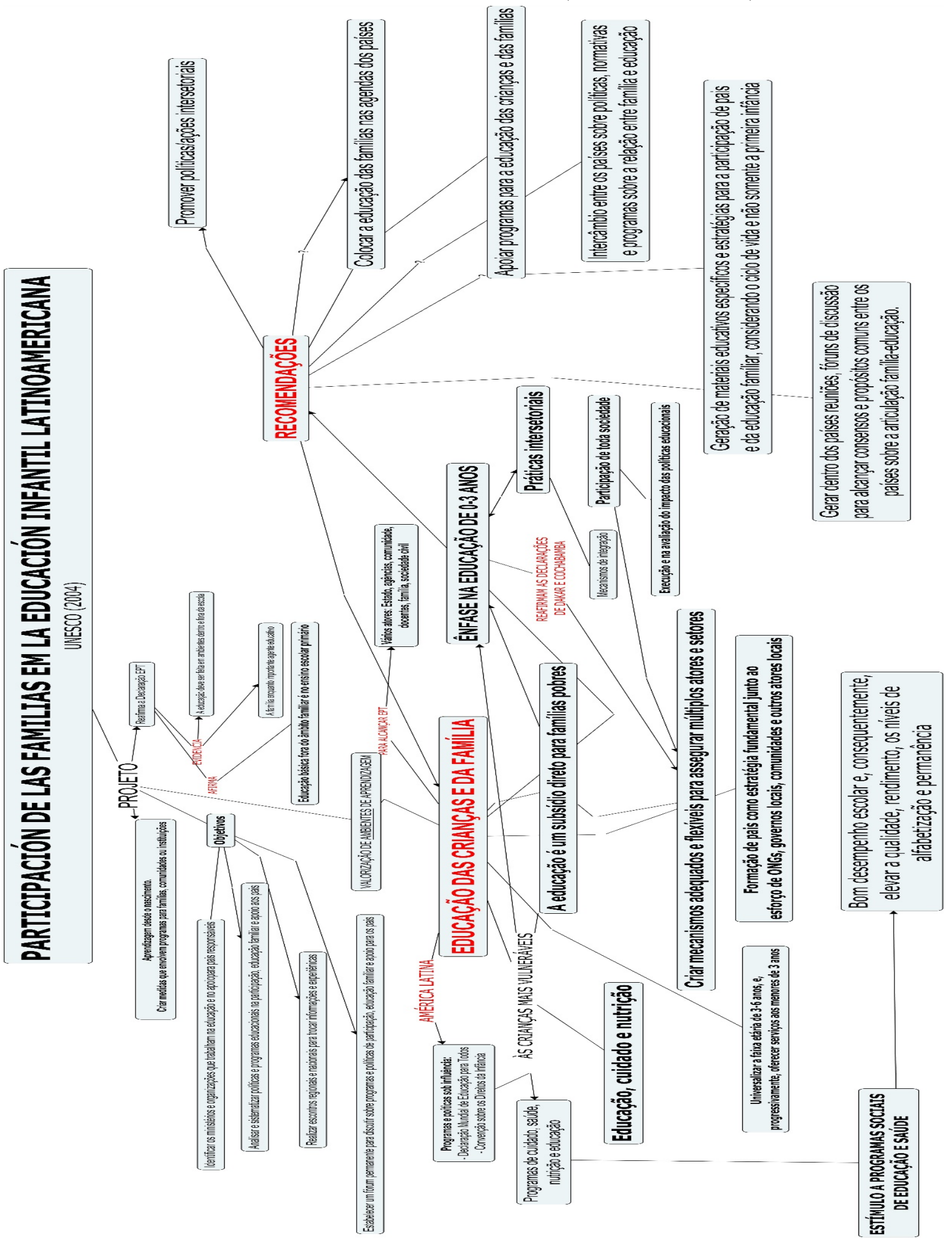

Fonte: Relatório Partipación de las Família em la Educación Infantil Latinoamericana, Unesco, 2004. Elaboração própria. 
Quanto ao documento Síntesis Regional de Indicadores de la Primera Infancia, a MC apresentou-se como mecanismo demonstrativo e avaliativo de ações desenvolvidas para a infância, a fim de suprir a escassez e a falta de comparação entre países de indicadores e estatísticas sobre educação e cuidados na primeira infância. Por meio do Escritório de Educação da UNESCO para a América Latina e o Caribe (OREALC/UNESCO) buscou-se apresentar orientações e ações para os países dessa região, apontando primeiramente relatórios nacionais Educação e Avaliação para Todos e estudos de caso na Bolívia, Chile, Colômbia e México. Isso marcou o primeiro passo para a construção de um conjunto abrangente e comparável de indicadores de sistemas nacionais de cuidados na primeira infância na América Latina. (UNESCO, 2004a)

O projeto objetivou desenvolver uma síntese regional de definições e indicadores existentes para a primeira infância. Em sua primeira fase, procurou cobrar definições e indicadores utilizados pelos países e produzir um documento que refletisse as condições e tendências com base em diferentes fontes de informação regionais e quatro estudos de caso. A esse respeito, não se visou analisar os números e o método de cálculo dos indicadores existentes, mas sim toma-los como exemplos da criação de orientações comuns aos países latino-americanos para a primeira infância.

Destaca-se o debate sobre saúde, nutrição e primeira infância, enfatizando aqueles mais vulnerabilizados, em programas de México e Chile, p.e., como modelo a ser seguido. A educação na primeira infância é tida como importante oportunidade para se assegurar melhores resultados na educação posterior, tendo em vista que uma experiência educativa bem-sucedida nos primeiros anos ocasiona importantes benefícios sociais, educativos e econômicos no futuro. (OREALC/UNESCO, 2004) 
FIGURA 2 - MC 2: SÍNTESIS REGIONAL DE INDICADORES DE LA PRIMERA INFANCIA (UNESCO, 2004B)

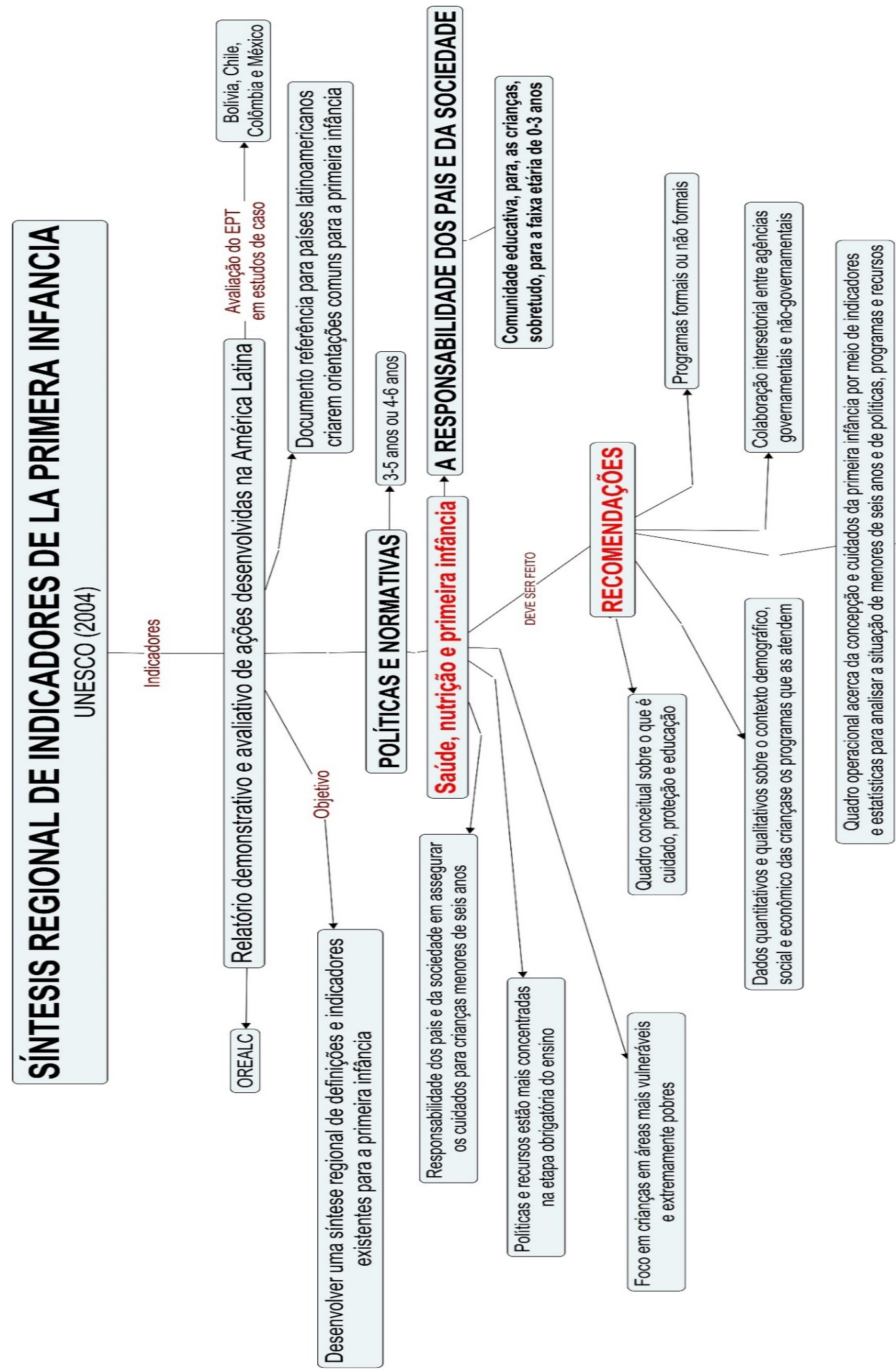

Fonte: Unesco, 2004b. Elaboração própria. 
Um debate que está na pauta das ações para a primeira infância denominado 'A responsabilidade dos pais e da sociedade', que discute como a 'comunidade educativa' pode se organizar para cumprir a educação das crianças, sobretudo de zero a três anos. Em relação às recomendações aos países, o relatório é objetivo sobre o que "os países devem fazer", enquanto "recomendaciones y desafios". Destas, elencamos as fundamentais para a etapa de análise deste artigo.

Logo em seu inicio, o documento enfatiza:"El aprendizaje comienza con el nacimiento. Ello exige el cuidado temprano y la educación inicial de la infancia. Estos requerimientos pueden enfrentarse a través de medidas que involucren programas para familias, comunidades o instituciones, según sea conveniente." ${ }^{\prime 4}$ (UNESCO, 2004a, p. 37) A questão da aprendizagem a partir do nascimento já expõe a preocupação com a Educação Infantil desde os primeiros meses de vida e coloca a sociedade civil, em especial a família, no centro dos programas para o cuidado desde cedo na infância. $\mathrm{O}$ documento reafirma o contido na Declaração Mundial de Educação para Todos, que evidencia a família enquanto importante agente educativo e como a educação deve ser feita dentro e fora da escola. Em relação aos especialistas que atuam em cada país, recomenda incluir componentes de participação, articulação, educação familiar nos programas de Educação Infantil e Educação Básica, dados os benefícios fornecidos para os adultos, meninos e meninas; avançar na geração de estratégias, metodologias, atividades e recursos didáticos apropriados para o trabalho com pais e mães, e com as famílias como ator social; avançar na geração de materiais educativos específicos para a participação de mães e pais e de educação familiar, considerando o ciclo de vida e não somente a primeira infância. (UNESCO, 2004)

Como percepção geral do documento, a família ocupa destaque nas ações educacionais para as crianças pequenas. O Relatório retorna a outros documentos da Unesco como a Declaração Educação para Todos e a Declaração de Cochabamba sobre a participação das famílias na educação das crianças pequenas, sobretudo das mais vulneráveis. A participação das famílias na escola apoiando as crianças é importante para o seu êxito no desenvolvimento, principalmente na educação de zero a três anos, e cabe às famílias e à comunidade estimular programas sociais que envolvam educação e saúde, para que a criança tenha um bom desempenho na educação primária.

O documento aponta uma tendência da região latino-americana de incluir a educação e orientação dos pais dentro da educação inicial, de modo que recebam a informação necessária para cuidar de seus filhos e aprendam atividades de estimulação adequadas para eles, mas, 
para além disso, é para cuidar e nutrir para o preparo na vida escolar e na venda da força de trabalho. Para afirmar tais aspectos, o relatório apresenta experiências exitosas latinoamericanas a fim de difundir experiências consideradas inovadoras e que estão alcançando bons resultados. Fazem parte das recomendações: a formação de pais; os programas para docentes sobre o trabalho com os pais; a formação de mães da comunidade para que executem programas de atenção às crianças; as campanhas massivas de informação, sensibilização e participação dos pais nos processos educativos em aula, na elaboração dos projetos educativos e institucionais e na gestão de recursos.

Entende-se que os documentos apontam os modelos como experiências a serem seguidas, visto que vários países da América Latina não criaram programas e/ou políticas de fortalecimento da primeira infância. Novamente, saúde, nutrição e educação estão na pauta. A ênfase do documento é na faixa de 3-5 anos ou 4-6 anos, idade de ingresso obrigatório na escola nos países da região. Vale destacar o forte debate sobre a colaboração intersetorial, tanto entre diferentes agências governamentais quanto entre estas e as organizações nãogovernamentais.

Apesar da ênfase na família, nem sempre se concebem pais e mães como atores individuais e sociais, com participação ativa no desenho e na gestão dos programas que apontem a educação de zero a três anos como função de vários atores e setores, como uma responsabilidade compartilhada; na maioria das vezes, eles são apenas receptores passivos de programas que integram educação e saúde na infância para o bom desempenho escolar e para o posterior 'sucesso' na alfabetização e na permanência na escola. A leitura dos relatórios permite constatar o quão se faz necessário ampliar os cuidados e a atenção à primeira infância, concluindo que esse nível educacional constitui oportunidade para se assegurar melhores resultados em escolaridade posterior, de forma que a experiência educativa nos primeiros anos de vida possibilite importantes benefícios sociais, educativos e econômicos.

$\mathrm{Na}$ questão da intersetorialidade, documento ressalta a participação sustentada de múltiplos atores e incentiva práticas intersetoriais no campo da educação, optando por uma espécie de 'divisão de tarefas' na gestão dos sistemas educativos: o provimento da oferta nos níveis considerados 'formais' fica sob responsabilidade público-estatal, o que se expressa nos elevados indicadores de matrículas das crianças de 4 a 5 anos nas unidades públicas; já a modalidade 'não formal', propalada no documento anterior da ONU, por ser considerada 'não escolar' e dirigida, na maioria dos países, às crianças de 0 a 3 anos, é objeto de uma formação 
compósita, dependendo majoritariamente de convênios ou 'parcerias' entre as esferas pública e privada, notadamente com as chamadas organizações sociais e conveniamentos.

Nesse segmento de 0 a 3 anos concentram-se também, na atualidade, boa parte dos programas de 'alívio à pobreza', como mostraremos mais adiante, integrando educação e saúde, educação das famílias, ambientes de aprendizagem - a dualidade entre educação formal e não-formal. Os termos vão se disseminando e se ressignificando ao longo das orientações, com menções a programas formais (oferta estatal), convencionais (de mães ou agentes da comunidade, que geralmente contam com uma formação de educação primária ou secundária) e não-convencionais (pessoas sem capacitação). Recomendações desse tipo podem afetar a qualidade desses programas e a ampliação da desigualdade, já que, geralmente, são dirigidos às crianças em contextos de maior vulnerabilidade, justamente as que mais necessitam de uma educação de qualidade para compensar essa situação de desvantagem.

O protagonismo da comunidade educativa para a educação de 0 a 3 anos é evidenciado nos documentos: como provedora e educadora, quando executam programas governamentais cujo alvo é o atendimento das crianças pequenas; como receptoras de educação ou de informações, quando são alvo de programas que visam à sua sociabilidade. As famílias são tomadas como parceira no compartilhamento da oferta dos serviços educacionais, pois a elas é atribuído o importante papel de mediadores sociais, acreditando-se no potencial educativo que possuem como meio para garantir as condições necessárias ao pleno desenvolvimento das crianças.

Chama a atenção a ausência de conceitos como primeira infância, cuidado, proteção. Por mais consensual que seja entre os países que a primeira infância começa com o nascimento, há uma predominância de pensar a educação das famílias e das crianças pela via da responsabilidade compartilhada, em que os três primeiros anos de vida se fazem em modalidades não-convencionais. Nesse sentido, organização de práticas intersetoriais asseguram parte da agenda educativa, que tem por objetivo homogeneizar a educação no planeta, bem como, segundo Evangelista e Shiroma (2007), produzir um discurso uniforme conforme inúmeros elementos comuns, produzindo, sobretudo, posições diferenciadas e afirmativas sobre o papel que ocupam na divisão internacional do trabalho ditadas pela hegemonia neoliberal.

Para além das recomendações, asseveramos o papel central dos organismos multilaterais enquanto agentes que desempenham ação fundamental de levar a mensagem 
hegemônica mundial, eivada de princípios, normas, regras, procedimentos e valores da cultura política mundial global que atribuem eficiência às organizações no que diz respeito à convergência de práticas nacionais. Consequentemente, as OIs têm um papel de veiculação da CEMC. Compreende-se, a partir de Dale (2001), que a AGEE se traduz na maneira como os Estados interpretam e respondem à CEMC estabelecida. A AGEE, assim, procura se colocar como uma força supranacional de caráter exemplar a serviço das políticas e práticas educativas nacionais no âmbito latino-americano, prefigurando tendencialmente a dinâmica geopolítica que envolve as políticas para a educação infantil e as concepções de integração na região. No geral, trata-se de pôr em prática uma agenda comum, institucionalizando a produção simbólica que se propõe ao longo do contexto de influência, conforme a elaboração conceitual de Ball (1992), recomendando políticas intersetoriais para educabilidade, gestão e infantilização da pobreza.

Nesse sentido, a educação das crianças pequenas tem sido objeto de orientações de diferentes organismos internacionais atuantes na América Latina, que extrapolam muitas vezes o âmbito da assistência técnica, dedicando-se também à execução direta ou ao apoio financeiro a programas implementados por agências governamentais ou não governamentais. As políticas implementadas nos últimos anos na região não resultam, exclusivamente, de políticas consensuais, visto que, como todo processo hegemônico, a perspectiva neoliberal em contexto de capitalismo globalizado, resultou de poderosas estratégias de coerção. Como projeto hegemônico de uma determinada classe social ela "se inscreve na lógica de continuidade e ruptura que caracteriza as formas históricas de dominação nas sociedades capitalistas." (GENTILI, 2002, p. 10) E essa lógica acentuou a pobreza na América Latina, conforme dados apresentados na Figura 3. 

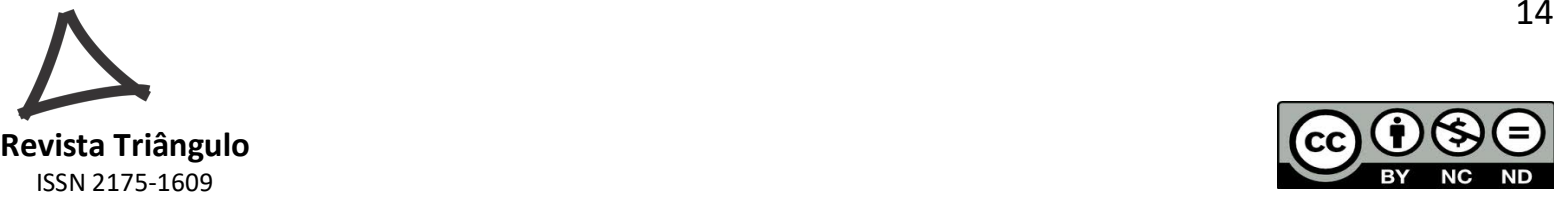

Figura 3 - Características da População latino-americana a partir de 1980

\section{América Latina: evolução da pobreza e da extrema pobreza, 1980-2014 a}

(Em porcentagens e millböes de pessoas)
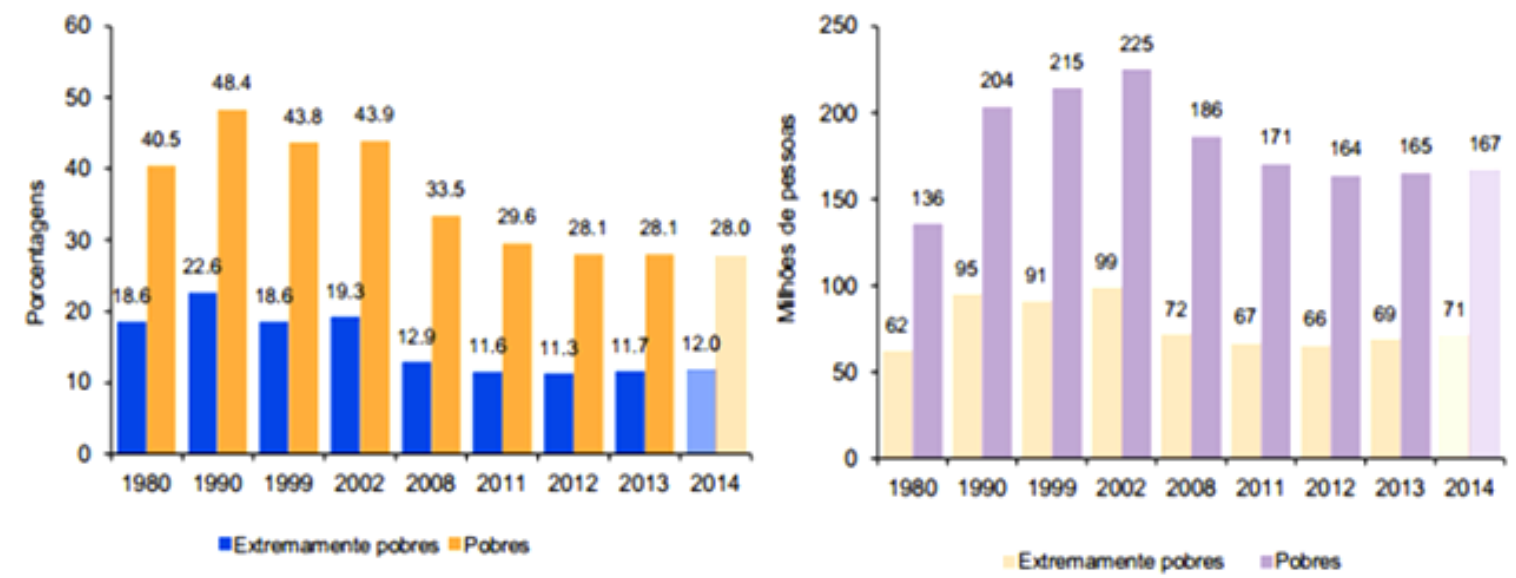

${ }^{a}$ Estimativa correspondente a 19 países de América Latina, incluído o Haiti. Não inclui Cuba.

${ }^{\mathrm{b}}$ As estatísticas de 2014 correspondem a uma projeção.

Fonte: Comissão Econômica para a América Latina e o Caribe (CEPAL), 2015, com base nas tabulações especiais das pesquisas por domicílio dos respectivos países.

O acirramento das contradições sociais, com o crescimento das desigualdades sociais expressas nos elevados índices de crescimento da pobreza e do desemprego na região latinoamericana, fez com que, nos anos de 1990, governos e organismos internacionais como BM, CEPAL, UNESCO e UNICEF passassem a apresentar proposições em favor de um ajuste com rosto humanizado, o que pode ser traduzido em políticas focalizadas e assistencialistas. Tais políticas induziram um processo de diminuição da pobreza, mas conseguido em grande medida pela benevolência de programas de transferência de renda, mantendo percentuais e contingentes de pobres ainda muito altos - quase 170 milhões de pessoas pobres e mais de 70 milhões na pobreza extrema.

O desencadeamento de várias reuniões, publicação de relatórios e desenvolvimento de diversas ações e programas apontam 'relativos consensos', sobretudo entre organismos internacionais, para o desenvolvimento de projetos, financiamentos e intervenções de governos nacionais e/ou de organizações não-governamentais que se concentram, 
especialmente, na definição de metas para a infância, em ações emergenciais e paliativas. Isso revela ainda o que Rosemberg (2002) apontou como conjugação de interesses internos e recomendações internacionais, pela qual é estabelecida coo prioridade a reforma da educação, tendo em vista atender as novas necessidades do desenvolvimento do país. A defesa fundamenta-se nos conceitos de capital humano que se expressa na educação, identificada como capital humano futuro, compreendendo a faixa etária em idade pré-escolar e de ensino fundamental, para as quais se predica o atendimento por meio de prática intersetoriais de saúde, educação, higiene e nutrição pelas quais promover a manutenção da pobreza se torna fundamental e estratégico.

\section{CONSIDERAÇÕES FINAIS}

Por meio da análise dos documentos internacionais aqui analisados, observa-se uma pauta de orientações e recomendações para a educação infantil nos países da América Latina que visa promover 'boas práticas', por meio de ações intersetoriais, bem como o intercâmbio em políticas e programas de participação, educação familiar e apoio para os pais àquelas crianças que se encontram em áreas mais vulneráveis e extremamente pobres dos países da região. Dessa forma, busca-se criar relativos consensos e/ou consensos possíveis entre os países, no sentido de integração de práticas para a infância, disseminando critérios e procedimentos de regulação e pesquisas e análises simbólicas que as justifique.

Os relatórios apresentam-se como expressão de boa vontade da 'face humanizada' do capitalismo, que coadunam as estratégias do capital para educar o consenso. Implicam, de um lado, a promoção de avanços na educação em sua relação com a pobreza, e por outro buscam a manutenção da força de trabalho futura, inclusive a de reserva. Nesse campo, o Estado, conforme Gramsci (1991), atua como mediador de atividades teóricas e práticas com as quais a classe dirigente justifica e mantém não somente a sua dominação, mas também consegue obter consenso ativo dos governados (famílias, crianças, trabalhadores).

A integração latino-americana por meio de práticas intersetoriais e internacionais pode ser considerada uma estratégia, construída pelos centros hegemônicos do capitalismo, de apresentar-se como receita universal para uma educação mundial lastreada nas necessidades do sistema de acumulação e implicado na regulação transnacional. Nesse breve estudo, apontaram-se as recomendações de práticas intersetoriais funcionando como um dos antídotos 

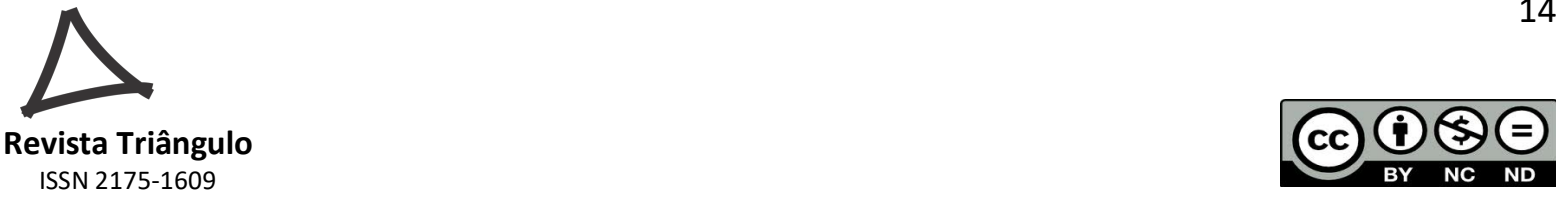

para alívio da pobreza e manutenção do capital humano futuro, o que prefigura, tendencialmente, uma dinâmica geopolítica que envolve e utiliza as políticas para a educação infantil na América Latina na construção de uma AGEE, agora convertendo-se em Agenda Regionalmente Estruturada para a faixa etária analisada.

\footnotetext{
${ }^{1}$ Reconhecida pela Declaração Universal dos Direitos do Homem, pelo Pacto Internacional sobre os Direitos Civis e Políticos (nomeadamente nos artigos $23 .^{\circ}$ e $24 .^{\circ}$ ), pelo Pacto Internacional sobre os Direitos Econômicos, Sociais e Culturais (nomeadamente o artigo $10^{\circ}$ ).

${ }^{2}$ Podemos citar os relatórios: Transformação produtiva com equidade (1990), Equidade e transformação produtiva: um enfoque integrado (1996), A lacuna da equidade (1997), Equidade, desenvolvimento e cidadania (1996).

${ }^{3}$ Foi desenvolvida já há uns anos por John Meyer, seus colegas e estudantes em Stanford, e o grupo é denominado de institucionalistas mundiais. (DALE, 2004)

4 "A aprendizagem começa no nascimento. Isto exige um cuidado a partir do nascimento e uma educação da primeira infância. Estes podem ser fornecidos por meio de medidas que envolvem programas para famílias, comunidades ou instituições, conforme o caso." (UNESCO, 2004a, p. 37)
}

\section{REFERÊNCIAS}

BALL, S.J. Educational reform: a critical and post-structural approach. Buckingham: Open University Press, 1994.

BID. Banco Interamericano de Desenvolvimento. Os primeiros anos: o bem-estar infantil e o papel das políticas públicas. Editado por: Samuel Berlinski, Nobert Schady. Washington: BID, 2016

BORTOT, Camila Maria. LARA, Ângela Mara de Barros. O kit educacional do UNICEF: Programa da Família Brasileira Fortalecida e suas implicações na gestão. Revista Administração Educacional - DAEPE-CE-UFPE, Recife-PE, v.9, n. 1 p. 42-65, jan/jun. 2018.

CAMPOS, Rosania. Educação Infantil e organismos Internacionais: uma análise dos projetos em curso na América Latina e suas repercussões no contexto nacional. Tese (doutorado em Educação). Universidade Federal de Santa Catarina, Florianópolis, 2008.

CARCANHOLO, Marcelo. Neoconservadorismo com roupagem alternativa: a nova Cepal dentro do Consenso de Washington. In: CASTELO, Rodrigo (Org.). Encruzilhadas da América Latina no século XXI. Rio de Janeiro: Zahar. 2010. p. 69-79.

CEPAL. La pobreza infantil: un desafío prioritário. Desafios: Boletín de la infancia y adolescencia sobre el avance de los objetivos del desarrollo del Milenio, n. 10, mayo de 2010. Santiago, Chile: CEPAL/UNICEF, 2010a. Disponível em: <www.eclac.org>. Acesso em: 11 nov. 2017. 


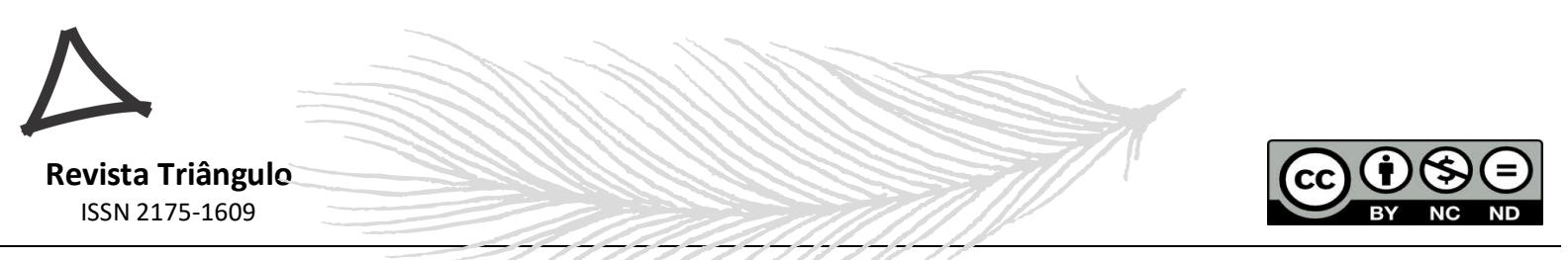

CEPAL. Panorama Social de América Latina. Santiago do Chile: CEPAL, 2015.

DALE, Roger, Globalização e educação: demonstrando a existência de uma 'cultura educacional mundial comum' ou localizando uma 'agenda globalmente estruturada' para a educação. Educação, Sociedade e Culturas, Porto, n. 16, p. 133- 169,2001.

DALE, Roger. Demonstrando a existência de uma "cultura educacional mundial comum" ou localizando uma "agenda globalmente estruturada para educação". Educação e Sociedade. v.25, no 87, Campinas/SP, mai/ago, 2004.

EVANGELISTA, Olinda; SHIROMA, Eneida Oto. Professor: protagonista e obstáculo da reforma. Educação e Pesquisa, São Paulo, v.33, n.3, p. 531-541, set./dez. 2007.

GRAMSCI, Antonio. Os intelectuais e a organização da cultura. Tradução de Carlos Nelson Coutinho. 8. ed. Rio de Janeiro-RJ: Civilização Brasileira, 1991.

MÉNDEZ, Emilio Garcia. G. Infância, lei e democracia: uma questão de justiça. In: MÉNDEZ, Emilio Garcia; BELOFF, Mary (Org.). Infância, lei e democracia na América Latina: análise crítica do panorama legislativo no marco da Convenção Internacional dos Direitos da Criança (1990-1998). Blumenau: Edifurb, 2001. p.21-46.

ONU. Organização das Nações Unidas. Declaração dos Direitos da Criança. Proclamada pela Resolução da Assembleia Geral das Nações Unidas n. ${ }^{\circ} 1386$ (XIV), de 20 de novembro de 1959.

ONU. Organização das Nações Unidas. Pacto Internacional sobre os Direitos Econômicos, Sociais e Culturais. Adotado e aberto à assinatura, ratificação e adesão pela resolução 2200A (XXI) da Assembleia Geral das Nações Unidas, de 16 de Dezembro de 1966. Entrada em vigor na ordem internacional: 3 de Janeiro de 1976, em conformidade com o artigo 27. .

PEREIRA, João Marcio Mendes. O Banco Mundial como ator político, intelectual e financeiros (1944-2008). Rio de Janeiro: Civilização Brasileira, 2010.

PINTO, Manuel; SARMENTO, Manuel Jacinto. As crianças: contextos e identidades. Minho. Portugal. Universidade do Minho / Centro de Estudos da Criança, 1997.

ROSEMBERG, Fúlvia. Organizações multilaterais, estado e políticas de Educação Infantil. Cadernos de Pesquisa, São Paulo, n.115, março 2002.

ROSEMBERG, Fúlvia; MARIANO, Carmem Lúcia Sussel. A convenção internacional sobre os direitos da criança: debates e tensões. Cadernos de Pesquisa, v.40, n.141, p.693-728, set./dez. 2010.

SÁ-SILVA, Jackson Ronie; ALMEIDA, Cristóvão Domingos de; GUINDANI, Joel Felipe. Pesquisa documental: pistas teóricas e metodológicas. Revista Brasileira de História \& 
Ciências Sociais v.1, n.1, jul. /2009. Disponível em: https://www.rbhcs.com/rbhcs/article/viewFile/6/pdf Acesso em: 18 Out. 2018.

SHIROMA, Eneida Oto; CAMPOS, Roselaine Fátima; GARCIA, Rosalba Maria Cardoso. Decifrar textos para compreender a política: subsídios teórico-metodológicos para análise de documentos. Perspectiva. v.23, n.2, p. 427- 446. jul./dez. 2005.

UNESCO. Síntesis regional de indicadores de la primera infancia. Santiago, Chile, mayo, 2004b. Disponível em: http://www.unesco.cl/medios/

UNESCO. Atención y educación de la primera infancia. Informe regional: América Latina y Caribe. Santigo, Chile, 2010. Disponível em: www.unesco.org . Acesso em: 10 jul. 2017.

UNESCO/OREALC. Participación de las familias en la Educación Infantil

Latinoamericana. Santiago, Chile, agosto, 2004a. Disponível em:

www.unesco.cl/medios/biblioteca/documentos/participacion_familias_educacion_infantil_lati noamericana.pdf . Acesso em: 22 Jun. 2017. 